\title{
Epistemología del Sur: una visión descolonial a los Objetivos de Desarrollo Sostenible
}

\author{
Javier Collado Ruano ${ }^{1}$
}

\begin{abstract}
Resumen: El objeto de investigación del presente artículo es identificar las diferentes perspectivas epistemológicas y metodológicas que han emergido desde el Sur global. También se aborda la irrupción de la globalización y los procesos transfronterizos del cambio climático desde la denominada "epistemología del sur". Como resultado, se manifiesta la necesidad de crear puentes transculturales entre los pueblos de todo el mundo para superar la encrucijada paradigmática en la que nos encontramos como sistema-mundo, con la finalidad de alcanzar los Objetivos de Desarrollo Sostenible establecidos por los Naciones Unidas para el año 2030.
\end{abstract}

Palabras clave: epistemología del sur, pensamiento fronterizo, transdisciplinariedad, globalización, estudios subalternos, paradigma otro, Objetivos de Desarrollo Sostenible, ecología de saberes, sistema-mundo, capitalismo.

Resumo: O objetivo de pesquisa do presente artigo é identificar as diferentes perspectivas epistemológicas e metodológicas que tem emergido desde o Sul global. Aborda-se também o surgimento da globalização e os processos transfronteiriços da mudança climática a partir da chamada "epistemologia do Sul". Como resultado, a necessidade de criar pontes transculturais entre os povos do mundo para superar a encruzilhada paradigmática onde estamos como sistema-mundo, com o fim de alcançar os Objetivos de Desenvolvimento Sustentável estabelecidos pelos manifestos das Nações Unidas do ano 2030.

Palavras chave: epistemologia do Sul, pensamento fronteiriço, transdisciplinariedade, globalização, estudos subalternos, paradigma outro, Objetivos de Desenvolvimento Sustentável, ecologia de saberes, sistema-mundo, capitalismo.

\footnotetext{
Abstract: The research object of this article is to identify the different epistemological and methodological perspectives that have emerged since the global South. It also addresses the irruption of globalization and cross-border processes of climate change from the called "epistemology of the South" perspective. As result, it claims the need for cross-cultural bridges between peoples worldwide to overcome the paradigmatic crossroads at which we find ourselves as a world-system, with the aim to achieve the Sustainable Development Goals set by the United

1 Doctor en "Difusão do Conhecimento" por la Universidad Federal de Bahía (Brasil). Doctor en Filosofía por la Universidad de Salamanca (España). Máster en Sociología de la Educación por la Universidad de Sevilla (España). Licenciado en Historia por la Universitat de València (España) con especialización en Relaciones Internacionales por la Universidad degli Studi di Palermo (Italia). Trabajó como Voluntario Internacional en proyectos de cooperación al desarrollo en las áreas rurales fronterizas de Perú y Ecuador. Presidente y fundador de la ONG "Educar para Vivir" (www.educarparavivir.com) Director de Edición del e-journal "Global Education Magazine", apoyado por la UNESCO y UNHCR (www.globaleducationmagazine.com). Puede leer sus trabajos, entrevistas y publicaciones en: www.javiercolladoruano.com . E-mail: javiercolladoruano@gmail.com .
} 
Nations for 2030.

Keywords: South epistemology, border thinking, transdisciplinarity, globalization, subaltern studies, another paradigm, Sustainable Development Goals, ecology of knowledge, world-system, capitalism.

\section{Breve introducción al paradigma de insostenibilidad actual}

La era de la globalización está en continua evolución, como la vida en la Tierra o el propio universo. La sociedad red del siglo XXI sigue expandiéndose multidimensionalmente en diferentes niveles de realidad (local, regional, nacional e internacional): generando una extensa red de interdependencia universal de fenómenos políticos, económicos, tecnológicos, ecológicos, culturales, etc. ${ }^{2}$ La competición económica caracterizada por el crecimiento irracional de las sociedades industriales ha puesto de manifiesto la insostenibilidad del sistema de producción capitalista para las futuras generaciones. La explotación de los recursos naturales de forma descontrolada es un tema de preocupación internacional donde diferentes actores geopolíticos internacionales, regionales, nacionales y locales- investigan y analizan, desde hace décadas, los fenómenos transfronterizos que afectan en la vida de las personas.

En septiembre de 2015 las Naciones Unidas han establecido un nuevo marco de acción para 2030 que requieren un esfuerzo de cooperación internacional: los Objetivos de Desarrollo Sostenible (ODS). Los ODS demandan una organización del conocimiento con nuevas fórmulas políticas transfronterizas puesto que constituyen un reto de gobernabilidad mundial sin precedentes históricos. Los ODS requieren desarrollar nuevas sinergias multidimensionales de carácter glocal $^{3}$ entre la ciudadanía planetaria actual y futura, especialmente en las zonas más desfavorecidas de África subsahariana y Asia meridional. No podemos mantener el orden socioeconómico capitalista actual, pues resulta incompatible con los límites del planeta Tierra. En palabras del filósofo moral Jorge Riechmann": "No hay recursos naturales ni espacio ecológico suficiente para que la forma de producir y consumir hoy dominante en Estados Unidos, la Unión Europea o Japón se extienda al planeta entero". La crisis económica y ecológica global es en realidad una crisis de civilización planetaria.

2 CASTELLS, Manuel. 2000. La era de la información. Vol. 1, la sociedad red. 2a ed. Torrejón de Ardoz: Alianza Editorial.

3 El término "glocal” es acuñado por R. Robertson (1992) y es un neologismo formado por las palabras globalización y localización. Para Robertson (1992), la globalización no implica una anulación de lo local, sino una inclusión, presencia y encuentro de y con las culturas locales.

4 Riechmann, Jorge. 2014. Un buen encaje en los ecosistemas. $2^{\mathrm{a}}$ ed. (revisada) de Biomímesis. Madrid: Ed. Catarata. P. 24. 
Dicho en otras palabras, el sistema capitalista no se puede universalizar al resto de la humanidad porque no existen recursos naturales suficientes que mantengan el estilo de vida occidental. En términos absolutos, "se necesitarían 1,5 planetas Tierras para satisfacer las demandas

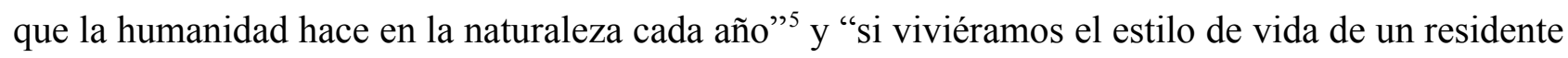
típico de EE.UU., necesitaríamos 3,9 planetas”“6. Esto significa que la especie humana está actuando como un virus que devasta la naturaleza: dejando una enorme huella ecológica ${ }^{7}$ en la Tierra que pronto nos hará entrar en colapso ecológico y civilizatorio, con desastrosas consecuencias para el medio ambiente y para la ciudadanía mundial más pobre y vulnerable.

Por esta razón, la ciudadanía global del siglo XXI necesita nuevas herramientas para comprender la realidad y herramientas para transformarla. Se requiere la formación, promoción e integración de una nueva consciencia humana que nos responsabilice con la situación de emergencia actual caracterizada por la insostenibilidad del sistema capitalista actual. Pero la creación de una auténtica educación libertadora que pretenda conseguir los ODS también implica una ruptura radical con las estructuras político-económicas y socio-educativas del pasado, ya que la educación tecnocrática todavía vigente en la mayoría de los ámbitos formales está basada en el modelo de organización social alienante que el capitalismo ha impuesto, desde la creación de los Estados modernos y la Revolución Industrial, para reducir a los estudiantes a consumidores sumisos y a ciudadanos pasivos.

La insostenibilidad generada por la sociedad post-industrial actual ha puesto de manifiesto la necesidad de crear, difundir y gestionar el conocimiento a través de un nuevo abordaje epistemológico que cuestione el legado recibido de la ciencia positivista que ha sido hegemónica entre los siglos XVIII y XX. Si bien es cierto que gracias a estas escuelas occidentales de pensamiento de reducción epistemológica hemos obtenido un gran desarrollo tecnológico y material, la propia especialización disciplinar ha puesto en jaque las fronteras conceptuales y metodológicas del reduccionismo epistemológico en que la ciencia moderna se apoyaba. Esta situación ha permitido la emergencia de nuevos diálogos entre las propias disciplinas científicas: la multidisciplinariedad, la pluridisciplinariedad, la interdisciplinariedad y la transdisciplinariedad. El conocimiento científico especializado (mono)disciplinar no puede tratar en solitario los problemas políticos, ecológicos y epistemológicos que los ODS demandan. Se necesita una ecología de

5 WORLD WILDLIFE FUND (WWF). Living Planet Report 2014. Species and Spaces, People and Places. 2014. P. 9.

6 Ibid. P. 36.

7 WACKERNAGEL, Mathis, REES, William E. Our Ecological Footprint. Reducing Human Impact on the Earth. Gabriola Island: New Society Publishers, 1996. 
saberes $^{8}$ cuyo abordaje epistemológico abarque los saberes no científicos subyacentes en las culturas ancestrales, la sabiduría indígena, las artes y otras formas de organización del conocimiento que incluyan las inter-retro-acciones del género humano consigo mismo, con el otro, con la naturaleza y con la totalidad cósmica que sustenta lo sagrado.

Por este motivo, debemos enfrentar la encrucijada paradigmática de los ODS desde una "ecología de saberes" que desarrolle y potencialice todas las dimensiones humanas mediante una organización transdisciplinar del conocimiento que combine la razón científica con otros aspectos epistémicos, espirituales, religiosos, afectivos, emocionales, políticos, retóricos, poéticos, artísticos y filosóficos. Sin duda, el diálogo con la sabiduría indígena y aborigen nos permitirá desarrollar nuevos horizontes epistemológicos más resilientes. Desde esta perspectiva cosmoderna ${ }^{9}$, la sostenibilidad se concibe como un fenómeno complejo donde el conocimiento científico del universo físico exterior converge con el conocimiento espiritual de un universo emocional interior. El modo introspectivo en que experimentamos y comprendemos los procesos que condicionan las formas de entendimiento e interpretación del mundo están en el núcleo mismo de las creencias paradigmáticas de una determinada época histórica. Así, la hegemonía de un cierto tipo de lectura de la realidad (o de los niveles de realidad), está impregnada en nuestro ser por el hecho de encontrarnos circunscritos a un paradigma concreto que actúa como referencial epistémico-cultural de nuestro mundo interior.

Esta reflexión conceptual de paradigma es fundamental para comprender los procesos de control simultáneo en la relaciones lógicas y semánticas de un determinado discurso que privilegia cierto tipos de relaciones en detrimento de otras ${ }^{10}$. Es lo que ocurre con el discurso cultural actual impuesto por el occidente capitalista al afirmar que todo crecimiento económico es bueno por sí mismo. En realidad, postular que los niveles de calidad humana se miden por el PIB y el PNB de un país supone cometer un fraude intelectual de peligrosas consecuencias en la era de la crisis ecológica global. Si bien es cierto que el sistema capitalista ha traído enormes beneficios materiales, su visión funcionalista subordina todo al máximo beneficio económico y al consumo indiscriminado en detrimento de la naturaleza. Todo lo que consumimos proviene de la regeneración biofísica de esta, que ya no da cuenta de los recursos demandados para mantener esta

8 SANTOS, Boaventura. 2010a. "Para além do pensamento abyssal: das linhas globais a uma ecologia de saberes". En Epistemologias do Sul, editado por Boaventura de Sousa Santos y Maria Paula Meneses 31-83. São Paulo: Cortez.

9 COLlado-RUANO, Javier, GALEFFI, Dante A., \& PONCZEK, Roberto I. The Cosmodernity Paradigm: An Emerging Perspective for the Global Citizenship Education Proposed by UNESCO. In: Transdisciplinary Journal of Engineering \& Science, TheATLAS, Vol. 5, pp. 21-34, 2014.

10 Morin, Edgar. 2008. Introdução ao Pensamento Complexo. Lisboa: Instituto Piaget. 
ilusión epistémica de crecimiento. Para rescatar las epistemologías de África debemos salir de estas dinámicas fatalistas que nos conducen a la barbarie, y para ello tenemos que reformular paradigmáticamente la relación colonial que los humanos ejercemos sobre la naturaleza, pero también sobre nosotros mismos. El pensamiento de frontera alberga la estrategia de que las clases marginales desafíen a las clases poderosas para lograr un mundo cosmopolita orientado hacia la justicia social y la equidad.

\section{"Un Paradigma Otro": una perspectiva epistémica del Sur global}

En las últimas décadas viene perfilándose un nuevo tipo de reflexión epistemológica descolonial que se sitúa del lado de la ciudadanía mundial del sur. Esta corriente de pensamiento cuestiona la dominación epistemológica occidental que eliminó y descontextualizó, durante siglos, el saber de los pueblos y de las naciones colonizadas. Se trata de una visión epistemológica conocida como epistemología del sur que se caracteriza por albergar un diálogo horizontal con los conocimientos de los subalternos colonizados en una ecología de saberes. Entre los pensadores más destacados que reflexionan a partir del sur encontramos a Enrique Dussel, Immanuel Wallerstein, Milton Santos, Ebrahim Moosa, Aníbal Quijano, Walter Mignolo, Boaventura de Sousa Santos, Ramón Grosfoguel, Nelson Maldonado-Torres, Mogobe B. Ramose, Amima Mama, Paulin Hountondiji, Rinajit Guha, Gayatri C. Spivak, Edward Said, Raewyn Connell, Dipesh Chakrabarty, Partha Chatterjee y otros muchos.

La complejidad de este movimiento es difícil de entender sin reconocer el esfuerzo colectivo e interdependiente que existe en el desarrollo de una epistemología del sur crítica con la historiografía que narra la modernidad y la postmodernidad desde posiciones eurocéntricas/occidentales. Se trata de un movimiento intelectual donde convergen diferentes líneas de investigación y percepción epistemológica entre pensadores que reivindican la presencia del sur global para transgredir el paradigma de imposición epistémica occidental de la sociedad globalizada actual. Una epistemología del sur que, en definitiva, "se asienta en tres orientaciones: aprender que existe el Sur; aprender a ir para el Sur; aprender a partir del Sur y con el Sur"11.

En un intento de originar distintos principios políticos, éticos, económicos y epistémicos de la civilización neoliberal actual, Walter Mignolo ${ }^{12}$ (2003) propone el concepto de "paradigma otro"

11 SANTOS, Boaventura de Sousa. 1995. Toward a New Common Sense: Law, Sciencie, and Politics in the Paradigmatic Transition. New York: Routledge. P. 508.

12 MignOLO, Walter. 2003. Historias Locales/Diseños Globales: Colonialidad, Conocimientos subalternos y pensamiento fronterizo. Madrid: Akal. 
en su obra "Historias locales/diseños globales: colonialidad, conocimientos subalternos y pensamiento fronterizo". En ella, Mignolo ${ }^{13}$ llama " "paradigma otro» a la diversidad de formas críticas de pensamiento analítico $y$ de proyectos futuros asentados sobre las historias $y$ experiencias marcadas por la colonialidad, dominantes hasta ahora, asentadas sobre las historias y experiencias de la modernidad". Este es "el conector" entre quienes han experimentado el trauma, la ignorancia, la falta de respeto y la imposición del "progreso" como un valor del bienestar. En palabras del propio filósofo, semiótico y especialista en estudios poscoloniales subalternos, Walter Mignolo:

«Un paradigma otro» es en última instancia el nombre que conecta formas críticas de pensamiento «emergentes» (como en la economía) en las Américas (latino/as; afroamericanos; americanos nativos; pensamiento crítico en América Latina y el Caribe), en el norte de África, en el África subsahariana, en el sur de India y en el sur de Europa, y cuya emergencia fue generada por el elemento común en toda esta diversidad: la expansión imperial/colonial desde el siglo XVI hasta hoy ${ }^{14}$.

De este modo, el "paradigma otro" tiene implícita la multirreferencialidad y la diversalidad en la unidad del conocimiento transdisciplinar, puesto que no tiene un autor de referencia ni un origen común. Se trata de un paradigma epistemológico que está en armonía con el concepto de rizoma epistemológico creado por Gilles Deleuze y Félix Guattari ${ }^{15}$ en su obra "Capitalismo y esquizofrenia", puesto que se trata de una corriente de pensamiento que aprehende las multiplicidades. Es decir, la genealogía de esta corriente epistemológica del sur se bifurca como el rizoma botánico entre la multiplicidad de historias locales y experiencias coloniales transformadas en crítica epistémica en diferentes espacios y momentos temporales.

Asimismo, Mignolo continua señalando que:

El «paradigma otro» es, en última instancia, el pensamiento crítico y utopístico que se articula en todos aquellos lugares en los cuales la expansión imperial/colonial le negó la posibilidad de razón, de pensamiento y de pensar el futuro. Es «paradigma otro» en última instancia porque ya no puede reducirse a un «paradigma maestro», a un «paradigma nuevo» que se autopresente como la «nueva» $\operatorname{verdad}^{16}$.

13 MIGNOLO, 2003, p. 20.

14 Ibid.

15 Deleuze, Gilles y, Félix Guattari. 2006. Mil mesetas: capitalismo y esquizofrenia. Valencia: Pre-Textos.

16 MIGNOLO, 2003, p. 20. 
Esta visión mignoliana significa que el "paradigma otro" no es coherente con el pensamiento epistemológico creado por la modernidad, pero tampoco con las críticas posmodernas eurocéntricas/occidentales que la globalización neoliberal tiene circunscrita en el raciocinio de científicos y filósofos, como sucede en los casos de Michael Foucault y Jacques Derrida, por ejemplo. La diferencia radica en que los movimientos intelectuales que critican la modernidad desde posicionamientos eurocéntricos/occidentales defienden "otro paradigma" posmoderno, uno "nuevo"; mientras que el grupo de pensadores que adoptan la perspectiva epistemológica de descolonización abogan por "un paradigma otro". La "otredad” del paradigma que Mignolo plantea lleva implícita la negación de la "novedad" y de la "universalidad abstracta" del proyecto moderno que continúa colonizando de forma invisible las mentes de los individuos.

Por eso Mignolo ${ }^{17}$ señala que "la hegemonía de «un paradigma otro» será, utopísticamente, la hegemonía de la diversidad, esto es, «de la diversidad como proyecto universal» y no ya un «nuevo proyecto abstracto». El autor enfatiza que su libro no es la "presentación" del paradigma otro, sino una "contribución” a él. Según la visión mignoliana, el "paradigma otro" está formado por proyectos que tienen en común la perspectiva y la crítica a la modernidad desde la colonialidad, es decir, por proyectos que surgen de la toma de consciencia de que no se trata de "diferencias culturales", sino de "diferencias coloniales" que ocultan la colonialidad del poder. Esta toma de consciencia origina un "pensamiento fronterizo" cuya perspectiva de descolonización suscita al diálogo entre los movimientos sociales y los intelectuales para superar el dominio de la política cultural colonial. Un buen ejemplo es el Foro Social Mundial llevado a cabo anualmente por un movimiento heterogéneo transfronterizo que aboga por una alter-globalización diferente. Este pensamiento fronterizo emergente permite recartografiar las culturas académicas y no académicas, uniendo y borrando las fronteras entre el conocer sobre y conocer desde, ayudando a imaginar un mundo sin fronteras rígidas (nacionales o de civilizaciones) donde el conocimiento surge con la propia vida, y no con los griegos.

En última instancia, la globalización representa una paradoja al establecer y demoler fronteras simultáneamente, de ahí que las viejas historias locales estén emergiendo de nuevo para proyectarse en el futuro, lo que significa la "diversidad como proyecto universal"18. Algunos ejemplos de historias locales emergentes que constituyen "un paradigma otro" son los movimientos

17 Ibid.

18 MIGNOLO, 2003, p. 390. 
indígenas en América Latina como el protagonizado por la guatemalteca Rigoberta Menchú ${ }^{19}$, el levantamiento del Ejército Zapatista de Liberación Nacional de 1994 en México, o la movilización indígena de la hondureña Berta Cáceres, cuyos paradigmas epistémicos hacen una disrupción con las directrices racionales occidentales que pretenden ordenar y controlar el cambio social.

Desde una perspectiva similar, Boaventura de Sousa Santos defiende una transición paradigmática que origine un "nuevo sentido común", ya que el paradigma cultural y epistemológico que se viene imponiendo globalmente como paradigma moderno y occidental es una versión construida en base a las necesidades de dominación colonial. La colonización es la otra cara de la moneda de la modernidad. Las experiencias culturales y epistemológicas que no estaban alienadas con el padrón moderno colonizador y capitalista eran reducidas, marginadas y relegadas a un segundo plano. De ahí que Santos ${ }^{20}$ defienda un occidente "no occidentalista", concordando con Goody $^{21}$ al pensar que una verdadera "historia global" sólo podrá ocasionarse en el momento en que se superen transdisciplinarmente las perspectivas eurocéntricas, anti-eurocéntricas, occidentales y orientales. Para Santos es posible combatir estas perspectivas a partir de una iniciativa interepistemológica asentada en una ecología de saberes y en las relaciones interculturales entre tradiciones. Esta concepción epistemológica alberga una paradoja, ya que la diversidad de experiencias humanas representan una pluralidad infinita de saberes epistemológicos en un mundo finito. En palabras del propio sociólogo del derecho portugués:

Siendo infinita, la pluralidad de saberes existentes en el mundo es intangible en cuanto tal, ya que cada saber sólo da cuenta de ella parcialmente, a partir de su específica perspectiva. Pero, por otro lado, como cada saber sólo existe en esa pluralidad infinita de saberes, ninguno de ellos se puede comprender a si mismo sin referirse a los otros saberes. El saber sólo existe como pluralidad de saberes tal como la ignorancia sólo existe como pluralidad de ignorancias. Las posibilidades y los límites de comprensión y de acción de cada saber sólo pueden ser conocidas en la medida en que cada saber se propone una comparación con otros saberes. Esa comparación es siempre una versión contraída de la diversidad epistemológica del mundo, ya que esta es infinita. Es, pues, una comparación limitada, pero es también un modo de presionar al extremo los limites y, de algún modo, de sobrepasarlos y

19 Rigoberta Menchu es una indígena maya guatemalteca que fue galardonada con el premio Nobel de la Paz en 1992, en reconocimiento a su lucha por la justicia social y la reconciliación etno-cultural basada en el respeto a los derechos de los indígenas.

20 SANTOS, Boaventura. "Um Ocidente não-ocidentalista? A filosofia à venda, a douta ignorância e a aposta de Pacal". En Epistemologias do Sul, editado por Boaventura de Sousa Santos y Maria Paula Meneses, 519-562. São Paulo: Cortez, 2010b.

21 Goody, Jack. 2006. The Theft of History. Cambridge: Cambridge University Press. 
deslocarlos. En esa comparación consiste lo que designo por ecología de saberes ${ }^{22}$.

Aquí concuerdo con Santos en que existe un número ilimitado de ecologías de saberes, tan infinito como la propia diversidad epistemológica y cultural que alberga la propia ciudadanía mundial, donde la inconmensurabilidad y la incompletitud del conocimiento -recordando los teoremas de Gödel- implica que los individuos hagamos una selección hermenéutica con los saberes paradigmáticos que interactúan en nuestro contexto dado. Esta dificultad es reconocida por el propio Santos al expresar que la propuesta conceptual de ecología de saberes confronta dos problemas: “a) cómo comparar saberes dada la diferencia epistemológica; b) cómo crear un conjunto de saberes que participa de un ejercicio dado de ecología de saberes ya que la pluralidad de saberes es infinita",23.

Para el primer problema de comparar saberes epistémicos diversos, Santos propone la traducción recíproca entre "señales, símbolos, conjeturas, enigmas, pistas, preguntas, paradojas, ambigüedades, etc." 24 . Para confrontar el segundo problema Santos aboga por la artesanía de las prácticas, es decir, un descentramiento de los saberes que promocione prácticas sociales eficaces y libertadoras a partir de una interpelación cruzada de los límites y de las posibilidades de cada uno de los saberes en presencia. Por ejemplo, "la preocupación de la preservación de la biodiversidad puede llevar a una ecología entre el saber científico y el saber camponés o indígena" ${ }^{25}$. Pero en ambos problemas Santos denota una asimetría compleja entre saberes epistemológicos que se manifiestan en mayor medida como asimetrías políticas. Al maximizar esta asimetría se incrementa la ignorancia respecto a otros saberes, llegando a declarar su inexistencia: "A este modo lo llamo fascismo epistemológico porque constituye una relación violenta de destrucción o supresión de otros saberes" ${ }^{26}$. En otras palabras, la supresión forzosa de conocimientos indígenas y ancestrales llevada a cabo por la colonización europea, que todavía continua hoy en día con nuevas formas neoliberales, es una forma de "epistemicidio" que empobrece al ser humano en su totalidad.

Por el contrario, al reconocerse esta asimetría entre los propios saberes, se minimiza la diferencia epistemológica a través de comparaciones y traducciones interculturales que posibilitan el entendimiento horizontal. De ahí que Santos proponga valorizar la diversidad de los saberes para que la intencionalidad y la inteligibilidad de las prácticas sociales sea lo más amplia y democrática

22 SANTOS, 2010b, p. 543.

23 SANTOS, 2010b, p. 544.

24 Ibid. P. 545.

25 Ibid. P. 546.

26 Ibid. P. 544. 
posible. Esta ecología de saberes es, en definitiva, una opción epistemológica y política contrapuesta al fascismo epistemológico impuesto por la expansión colonial europea.

Desde una perspectiva similar a Santos, el sociólogo y teórico político peruano Aníbal Quijano desarrolla el concepto de colonialidad a partir de un análisis de la situación latinoamericana. Influenciado por el pensamiento de Marx y Gramsci, Quijano hace una interpretación epistémica de la situación de dominación presente en el Sur global. Para este autor la destrucción de la colonialidad del poder es uno de los factores determinantes de la lucha contra el padrón universal del capitalismo eurocéntrico/moderno. “La «racionalización» de las relaciones de poder entre las nuevas identidades sociales y geoculturales fue el sustento y la referencia legitimadora fundamental del carácter eurocéntrico del padrón de poder, material e intersubjetivo"27. Por esta razón, el pensador peruano cuestiona la naturalización de las experiencias, las identidades, las relaciones históricas de la colonialidad y la distribución geocultural del poder capitalista mundial, estableciendo un esquema para el estudio de estas implicaciones paradigmáticas: 1) colonialidad de la clasificación social universal del mundo capitalista; 2) Colonialidad de la articulación política y geocultural; 3) Colonialidad de la distribución mundial del trabajo; 4) Colonialidad de las relaciones de género; 5) Colonialidad de las relaciones culturales o intersubjetivas; y 6) Dominación/explotación, colonialidad y corporeidad.

En este análisis diferencial de colonialidad también destaca la propuesta radical de geopolítica descolonial propuesta por el especialista en estudios étnicos Nelson MaldonadoTorres $^{28}$, quien realiza un análisis crítico de varios filósofos europeos contemporáneos para manifestar que la filosofía moderna occidental convirtió a Europa en el centro epistémico del mundo. De un modo complementario, Ramón Grosfoguel ${ }^{29}$ propone ampliar el debate epistémico sobre descolonialidad y capitalismo global desde una perspectiva crítica del nacionalismo, del colonialismo y del fundamentalismo (sea éste eurocéntrico o del llamado Tercer Mundo). La crítica epistemológica que Grosfoguel realiza sobre los estudios dedicados a la globalización, a los paradigmas de la economía política y a los análisis del sistema-mundo, es que estos no logran desprenderse de la matriz epistémica del poder: "El posmodernismo y el post-estructuralismo como proyectos epistemológicos están atrapados en el canon occidental reproduciendo en sus esferas de

27 QUIJANO, Aníbal. "Colonialidade do poder e classificação social. En Epistemologias do Sul, editado por Boaventura de Sousa Santos y Maria Paula Meneses. São Paulo: Cortez, 2010. P. 119-120.

28 TORRES, Nelson. A topologia do ser e a geopolitica do conhecimento. Modernidade, império e colonialidade. En SANTOS, Boaventura de Sousa, y MENESES, Maria Paula (org.), Epistemologias do Sul. Pp. 396-443. São Paulo: Cortez, 2010.

29 GROSFOGUEL, Ramón. "La desconolinazión de la economía política y los estudios postcoloniales: Transmodernidad, pensamiento fronterizo y colonialidad global”. En Tabula Rasa, № 4, 17-48, Bogotá, 2006. 
pensamiento y de práctica una forma particular de colonialidad del poder y el conocimiento" 30 . Para salir del paradigma epistémico eurocéntrico/occidental moderno, colonial, capitalista y patriarcal, Grosfonguel apunta experiencias alternativas construidas a partir de un pensamiento de frontera cuyos proyectos utópicos tienen como objetivo la emancipación de las relaciones de poder en el sistema-mundo. Preguntándose “¿cómo se ve el sistema-mundo si movemos el locus de enunciación del hombre europeo a una mujer indígena en América, a, digamos, Rigoberta Menchú, en Guatemala, o a Domitila, en Bolivia?’31, Grosfoguel consigue desplazar el lugar desde el cual están pensados los paradigmas. Con ello, también consigue poner en tela de juicio la perspectiva económica reduccionista del sistema-mundo, ya que la colonización de América a finales del siglo XV ocasionó, de manera simultánea, una compleja jerarquía epistémica paradigmática impuesta por el "hombre europeo, capitalista, militar, cristiano, patriarcal, blanco, heterosexual" 32 . Sin duda, el planteamiento epistémico desde una perspectiva subalterna racial y étnica consigue transgredir y descolonizar los paradigmas epistémicos tradicionales donde la economía política conceptualiza el capitalismo como un sistema global o mundial.

Los procesos y las dinámicas neoliberales que la globalización viene desarrollando han creado una lógica epistémica paradigmática donde se prima el beneficio económico del mercado frente a la dignidad, la seguridad e incluso la misma supervivencia del ser humano. Existe la sensación de que la vida ha dejado de constituir el valor central del proyecto civilizatorio humano en la Tierra. El mundo sagrado de los pueblos originarios, donde la naturaleza es venerada por su carácter mágico, se ha visto remplazado por paraísos fiscales que satisfacen la avaricia y la codicia mercantil humana. Ante esta peligrosa situación que se evidencia particularmente en el Sur global a excepción de Australia y Nueva Zelanda-, el filósofo especialista en ciencias políticas y relaciones internacionales Mogobe B. Ramose analiza la globalización a partir del concepto ubuntu, preguntándose “¿puede la filopráxis ubuntu ser una de las respuestas al fundamentalismo económico contemporáneo en forma de globalización?" ${ }^{33}$. Ubuntu es uno de los conceptos filosóficos, ontológicos y éticos africanos que actúa como principio organizador esencial de los pueblos que hablan lenguas Bantúes, los cuales permanecen abiertos a cooperar con todos los seres humanos del mundo que buscan sustituir el fundamentalismo económico imperante en la globalización por la preservación de la vida.

30 Ibid. P. 21.

31 Ibid. P. 24.

32 Ibid. P. 25.

33 RAMOSE, Mogobe B. "Globalização e Ubuntu”. En Epistemologias do Sul, editado por Boaventura de Sousa Santos y Maria Paula Meneses, São Paulo: Cortez, 2010. P. 179. 
Como es sabido, las lenguas bantúes constituyen una subfamilia de lenguas Níger-Congo que son habladas en Angola, Botsuana, Camerún, Gabón, Kenia, Malaui, Mozambique, Namibia, República del Congo, República Democrática del Congo, Sudáfrica, Tanzania, Uganda, Zambia y Zimbabue. Para Ramose "la globalización puede ser cultural, religiosa, política y económica, [de ahí que sea] posible describir tal situación como una condición de dominación epistemológica empeñada en suprimir la búsqueda de reconocimiento mutuo y de paridad" ${ }^{34}$. Las raíces de la globalización contemporánea están profundamente arraigadas a la Revolución Industrial, particularmente en el Reino Unido, y con la subsecuente difusión e imposición global de este modelo económico a través de la colonización durante los viajes de "descubrimiento". A pesar de la descolonización y la "reconquista" de la soberanía de los Estados-Nación (casi siempre con largas guerras de independencia), las redes económicas de dominación han permanecido en el Sur global por el carácter epistémico paradigmático que se sustenta en la búsqueda incansable de mano de obra barata en la "periferia" del mundo. En palabras de Ramose:

El dislocamiento de la industria, la desregulamentación, las redes y la obtención del máximo lucro a cualquier costo constituyen el doma de la religión del fundamentalismo económico. Las sacerdotisas y los sacerdotes de esta religión predican apenas el evangelio y veneran apenas un dios, principalmente, la lucratividad del mercado. Para ellos, el mercado es el poder financiero que sustenta la contradicción del espacio, del tiempo y de la política, sin importarles las posibles consecuencias humanas y ambientales. La obtención de lucros sin restricción es su principal meta. Bendecidos, por tanto, son los creadores del lucro infinito, pues ellos substituyeron la ilusión del cielo eterno por el lucro infinito del mercado ${ }^{35}$.

A través de la identificación de alguna de las líneas principales de dominación económica, política, cultural y epistemológica, Ramose cuestiona la religión del fundamentalismo económico presentando la alternativa africana ubuntu como una propuesta epistemológica que inspira otra forma de ser y estar en el mundo: "ubuntu indica, por tanto, una acción particular ya realizada, una acción o estado duradero de ser y una posibilidad para otra acción o estado de ser" ${ }^{36}$. De este modo, Ramose apunta que la filosofía africana ubuntu reconoce que los procesos de intercambio perpetuo de flujos de energía, adyacente en las fuerzas de la vida en la naturaleza, no pertenecen a nadie. 
Haciendo alusión a dos tesis encontradas en la mayoría de lenguas africanas, "Motho ke motho ka batho" y "Feta kgomo o tshware motho”, Ramose procura problematizar con la organización social y económica mundial, contribuyendo a establecer una nueva perspectiva epistémica paradigmática para el debate internacional de los derechos humanos.

El significado esencial del primer aforismo postula que "ser humano es afirmar la humanidad propia a través del reconocimiento de la humanidad de los otros $\mathrm{y}$, sobre tal embasamiento, establecer relaciones humanas respetuosas para con ellos"37. Este principio de reconocimiento mutuo significa que el ser humano individual es un sujeto (y no un objeto) de valor intrínseco en sí mismo, en la medida en que reconoce la dignidad del otro. Despreciar al otro significa despreciarse a sí mismo. Los individuos somos entidades inacabadas que sólo revelamos nuestras potencialidades y habilidades a través de las relaciones humanas. En la línea de este argumento, Ramose señala que "la filosofía africana indígena de los derechos humanos avanza a partir de la dignidad del ser humano y de la negación del absolutismo y del dogmatismo" ${ }^{\# 8}$.

Por otro lado, el segundo aforismo significa que cuando una persona se encuentra en la disyuntiva de escoger entre la riqueza y la preservación de la vida de otro ser humano, debe optar por la preservación de la vida. De acuerdo con esta premisa filosófica, el ser humano individual debe ser considerado como el valor básico y principal de todos los valores, ya que la organización social y política basada en la riqueza son la fuente de conflictos y guerras. En este aforismo africano existe una gran diferencia conceptual con la filosofía occidental de los derechos humanos, ya que, si bien es cierto que la concepción occidental también parte del principio de que el ser humano individual es el principal criterio de valor, hace mayor énfasis en "la idea del ser humano como una entidad fragmentada sobre la cual los derechos pueden ser agregados en la base de contingencia”, a diferencia de la concepción africana que "subraya la idea del ser humano como una totalidad, teniendo sus derechos asegurados como tal" ${ }^{\prime 39}$.

La toma de consciencia entre las diferencias epistémicas de la filosofía occidental y la filosofía africana deben guiarnos para la superación paradigmática que la globalización capitalista actual impone al resto del mundo, haciendo prevalecer la opción de preservar la vida en la Tierra ante las lógicas de enriquecimiento materialista impuestas por una minoría. Debemos hacer autocrítica del meta-sistema actual guiado por la irracionalidad económica de la globalización y debemos abordar la política internacional a través de una nueva concepción pluralista y polilógica

37 Ibid. P. 212.

38 Ibid.

39 Ibid. P. 213. 
de la ética, que inspire nuevos rumbos de navegación por las aguas del siglo XXI.

Por este motivo, necesitamos reformular la ética humana y realizar un esfuerzo metacognitivo intelectual, moral y afectivo que advierta la complejidad de los ODS desde la perspectiva filosófica $u b u n t u$, cuyo polimorfismo etológico representa la sabiduría de aprender a crecer juntos como sociedad globalizada. Por este motivo, resulta imprescindible que todos los actores socioeducativos promovamos la filosofía africana ubuntu como meta-estructura de pensamiento, sensibilización y entendimiento de la convergencia evolutiva sociobiológica y antropoética, puesto que la simbiosofía pluricultural ubuntu constituye un elemento emergente para la gestión ética de nuestro futuro común como especie en armonía con las otras formas de vida en la naturaleza.

Una lectura similar es realizada por Dismas A. Masolo ${ }^{40}$ desde la ética aplicada y la filosofía política y social, valorizando el conocimiento indígena africano desde formas epistemológicas que evitan las categorías coloniales oposicionales del tradicional y del moderno. En este sentido, Paulin Hountondji también identifica dos perspectivas sobre los estudios africanos -el conocimiento de África y los conocimientos africanos-, y con ello abre camino para una discusión sobre la naturalización del conocimiento en cuanto símbolo de persistencia de la relación colonial. Hountondji defiende que otra producción del conocimiento deberá producirse "a la par de una reapropiación crítica de los propios conocimientos endógenos de África y, más que eso, con una apropiación crítica del propio proceso de producción y capitalización del conocimiento" ${ }^{41}$. Esta actitud crítica también aparece en el pensamiento del teólogo Ebrahim Moosa ${ }^{42}$, que hace una lectura de la dicotomía entre el islam tradicional y el islam progresista a partir su experiencia en la comunidad musulmana minoritaria en la Sudáfrica del apartheid (segregación racial).

Todas esas perspectivas epistemológicas de descolonización también se han desarrollado ampliamente en la India. La obra "Elementary Aspects of Peasant Insurgency in Colonial India” del historiador hindú Ranajit Guha es considerada un clásico en el Sur Asiático por su influencia en los estudios subalternos de la década de 1980. Repensando el término subalterno definido por el italiano marxista Antonio Gramsci, que se refiere a aquellas personas o grupos de rango y posición inferior, bien sea por causa racial, de clase, género, orientación sexual, etnicidad o religión; el grupo de trabajo South Asian Subaltern Studies, formado por Guha y sus discípulos, hacen una crítica a la

40 MASOLO, Dismas A. 2010. "Filosofia e conhecimento indígena: uma perspectiva africana." En Epistemologias do Sul, editado por Boaventura de Sousa Santos y Maria Paula Meneses, 313-240. São Paulo: Cortez.

41 HOUNTONDJI, Paulin J. "Conhecimento de África, conhecimentos africanos: duas perspectivas sobre os estudos africanos". En Epistemologias do Sul, editado por Boaventura de Sousa Santos y Maria Paula Meneses. São Paulo: Cortez, 2010. P. 141.

42 MOOSA, Ebrahim. "Transições no "progresso" da civilização: teorização sobre a história, a prática e a tradição". En Epistemologias do Sul, editado por Boaventura de Sousa Santos y Maria Paula Meneses, 291-312. São Paulo: Cortez, 2010. 
narrativa tradicional marxista sobre la historia de la India. Desde la perspectiva de estudios subalternos, la preocupación por la política y el poder abre un proceso de "deconstrucción" epistémica paradigmática en la historiografía, donde se busca reescribir la historia de la India a partir de la lucha entre el subalterno y la élite, es decir, entre las masas indígenas y la soberanía británica. En palabras del propio Guha:

La historiografía del nacionalismo indio ha sido dominada por largo tiempo por un elitismo — elitismo tanto colonialista como de la burguesía nacionalista— que compartía el prejuicio de que la construcción de la nación india y el desarrollo de su conciencia — su nacionalismo - que confirmaba este proceso, eran logros que pertenecían exclusiva o predominantemente a una élite. En las historiografías colonialistas y neo-colonialistas estos logros se atribuían a la dominación británica, a los administradores coloniales, a sus agentes de control policial, a sus instituciones y a su cultura. En los escritos nacionalistas y neo-nacionalistas se atribuirían ahora a las personalidades, a las instituciones, a las actividades y a las ideas de una élite india ${ }^{43}$.

De este modo, Guha muestra que la alternativa subalterna es un conocimiento integral para superar todas las lagunas, lapsos e ignorancias que el nacionalismo indiano alberga en su narración tradicional. Su afirmación es que la perspectiva del ser subalterno puede comprender toda la experiencia de la resistencia indígena al colonialismo británico de forma más justa y pertinente que las historias parciales proporcionadas por un grupo de líderes nativos dominantes o historiadores coloniales. Es decir, su posicionamiento epistémico como subalterno cambia estructuralmente el marco epistémico paradigmático creado por las élites occidentales y (post)coloniales en su narración historiográfica. De ahí que la filósofa y teórica literaria hindú Gayatri Chakravorty Spivak $^{44}$ escribiese su ensayo “¿Puede el subalterno hablar?”, donde, en armonía con Guha, discute la precaria normatividad de esta narración historiográfica. Spivak afirma que esta precariedad se pone de manifiesto cada vez que el capitalismo occidental establece la universalidad del modo narrativo de producción, y que el hecho de ignorar al individuo subalterno supone continuar con el proyecto imperialista.

El pensamiento crítico postcolonialista de Spivak apunta que este proceso historiográfico de

43 GUHA, Ranajit. Subaltern Studies I: Writing on South Asian History and Society. New Delhi: Oxford University Press, 1982.

44 SPIVAK, Gayatri Chakravorty. ¿Puede hablar el subalterno?. Buenos Aires: El cuenco de plata, 2011. 
enfoque eurocéntrico influencia diferentes niveles epistémicos paradigmáticos: global, nacional y local. Poniendo el ejemplo de la abolición del ritual hindú Sati (donde las mujeres indígenas se suicidaban en los funerales de sus maridos), por parte del hombre blanco para proteger a la mujer indígena, Spivak reflexiona críticamente sobre la posibilidad de hablar de los subalternos. Para Spivak, el subalterno oprimido se ve obligado a adoptar costumbres occidentales de conocimiento, pensamiento, razonamiento y lenguaje con el fin de ser oído y atendido. Debido a esta occidentalización, la población subalterna se ve cohibida de reconocer sus propia cosmovisión epistemológica y en su lugar debe adoptar una visión epistémica occidental para conocer su mundo no-occidental.

En la obra "Selected Subaltern Studies" coordinada conjuntamente entre Guha y Spivak, Spivak ${ }^{45}$ hace una lectura vigotskyana para superar este proceso de "internalización” del sujeto subalterno a través de la mediación cultural dialógica: “el diálogo para Vigotsky es el ejemplo privilegiado de la denominada comunicación de verbalidad directa entre dos autores o fuentes inmediatamente auto-presentes". A través del reconocimiento de la acción dialógica, Spivak considera que se produce un cruce de líneas que dan acceso a la "micrología" del mundo filosófico de los Estudios Subalternos. En armonía con esta tendencia que incentiva la creación de identidades propias del mundo subalterno, el científico social hindú especialista en tecnologías Shiv Visvanathan $^{46}$ apela a las heurísticas y a las experiencias de pluralidad, diversidad y complejidad como las bases para nuevos encuentros culturales.

Todas estas perspectivas de intelectuales latinoamericanos, africanos, islámicos e hindúes ponen en evidencia la influencia nociva de la colonialidad, así como la subsecuente imposición de saberes epistémicos eurocéntricos y occidentales. Estas perspectivas epistemológicas del sur nos obligan a pensar el meta-paradigma de los ODS desde un marco pluriversal y multirreferencial, en vez de un único modelo monocultural que intente concretizarse como un diseño global. La diversidad epistémica es el único proyecto universal que toda educación libertadora puede diseñar para no caer en el "epistemicidio". El reconociendo democrático de otras cosmovisiones epistemológicas provenientes de la población indígena latinoamericana, africana, islámica y asiática deben reconceptualizar la democracia liberal europea/occidental que se viene imponiendo paradigmáticamente $\mathrm{y}$ transgredir transcendentalmente su matriz epistémica a través de un pensamiento crítico de frontera capaz de establecer un diálogo horizontal entre todos los pueblos del

45 GUHA, Ranajit; SPIVAK, Gayatri Chakravorty. Selected Subaltern Studies. New York: Oxford University Press, 1988. P. 24.

46 VISVANATHAN, Shiv. "Cultural Encounters and the Orient: a Study in the Politics of Knowledge”. En Diogenes, $50(4), 69-81,2003$. 
mundo.

Debemos enfocar nuestra mirada en el horizonte paradigmático de los ODS a escala planetaria, buscando construir un mundo donde otros mundos sean posibles, lo que implica reconocer transculturalmente el inmenso jardín que constituye la humanidad. Un jardín en constante proceso evolutivo donde la ciudadanía mundial representa la belleza de una diversidad infinita de flores que deben reconciliar el pasado, el presente y el futuro, para crear una civilización planetaria en armonía medioambiental. Metafóricamente, se trata de una polinización transcultural entre las diversas sociedades etno-culturales que encuentra en la transdisciplinariedad la herramienta epistemológica para construir puentes espirituales y científicos que interconecten las naciones y los pueblos del mundo, sin privilegiar espacio o tiempo cultural que juzgue o jerarquice la convivencia en el hábitat común de la Tierra.

En este sentido, el fundador de la Sociedad Brasileña de Etnomatemáticas Ubiratan D 'Ambrosio ${ }^{47}$ señala: "La transdisciplinariedad reposa sobre una actitud abierta, de respeto mutuo y de humildad con relación a mitos, religiones y sistemas de explicaciones y de conocimiento, rechazando cualquier tipo de arrogancia o prepotencia”. Estamos aquí para aconsejarnos mutuamente: plantando semillas de amor y de justicia. De ahí la importancia de las connotaciones filosóficas derivadas de la mecánica cuántica para considerar la entelequia de un espacio-tiempo cultural, religioso, político, artístico o educativo que no pueda jerarquizar los cuadros epistémicos paradigmáticos construidos por el ser humano en su caminar histórico. La transdisciplinariedad representa, entonces, la metodología apropiada para enfrentarnos a la encrucijada paradigmática que representan los ODS.

\section{Últimas reflexiones para abordar la encrucijada paradigmática actual}

El escenario internacional actual de post-guerra fría nos incita a pensar que todavía no nos hemos librado de nuestra espada de Damocles contemporánea: la amenaza nuclear. Entre los años 1958 y 1962, los Estados Unidos (EE.UU.) y la antigua Unión Soviética (URSS) estuvieron realizando pruebas de explosión nuclear en el espacio exterior, en tierra firme y debajo del agua oceánica. Según estadísticas razonablemente completas, se cree que la URSS y los EE.UU. (y marginalmente otros países tecnológicamente avanzados), han lanzado alrededor de 2.200 satélites militares entre 1959 y 1983, duplicándose esa cifra entre los años 1984 y 2000. Según el “Stockholm International Peace Research Institute” (SIPRI) ${ }^{48}$, a principios de 2015 nueve países

47 D’AMBROSIO, Ubiratan. Transdisciplinaridade. São Paulo: Palas Athena, 1997. P. 80.

48 SIPRI (Stockholm International Peace Research Institute). Yearbook 2015. Armaments, Disarmament and 
(Estados Unidos, Rusia, Reino Unido, Francia, China, India, Pakistán, Israel y la Corea del Norte) poseían unas 15.850 armas nucleares, de las cuales 4.300 estaban desplegadas con fuerzas operativas. Alrededor de unas 1.800 de estas armas se mantienen en un estado de alerta operativa alta, representando, literalmente, "espadas de Damocles contemporáneas".

A diferencia de otras guerras que se han desarrollado durante el transcurso de la historia humana, la potencialidad nuclear para erradicar cualquier forma de vida en la Tierra ha cambiado paradigmáticamente las normas del juego en las relaciones internacionales, puesto que cualquier grupo terrorista o Estado-Nación soberano podría destruir el mundo tal y como lo conocemos. Si bien este ultimátum paradigmático que coacciona el desarrollo de la sociedad del riesgo mundial ${ }^{49}$ no parece ser un motivo de alarma para crear mecanismos eficaces de gobernabilidad planetaria que gestionen una cultura de paz; la degradación del medio ambiente derivada de nuestros sistemas de producción y consumo ha puesto de manifiesto la insostenibilidad de nuestras prácticas de explotación a la naturaleza. "Es preciso, pues, construir esos puentes de comunicación entre campos distintos y cuidar la vida en el planeta cuanto sea posible con unas perspectivas biopolíticas revolucionarias y convergentes", argumenta el filósofo Luciano Espinosa ${ }^{50}$. El cumplimiento de los ODS nos obliga a construir puentes biopolíticos que combinen los diversos conocimientos y saberes para transcender el cuadro epistémico que constituyen nuestras creencias, hábitos, actitudes y valores.

Estamos ante una encrucijada paradigmática que concierne a toda la ciudadanía mundial, sin importar nuestra raza, etnia, cultura, religión o nacionalidad jurídica. La amenaza de un holocausto nuclear y las previsiones de un colapso ecológico (cambio climático, calentamiento global, pérdida de la biodiversidad, etc.) nos compela a desarrollar una profunda transformación en las relaciones del ser humano consigo mismo, con el otro, con la naturaleza y con lo sagrado. Por eso no podamos excluir ningún tipo de conocimiento o cosmovisión epistémica, bien sea una creencia indígena, una conceptualización artística, una intuición espiritual, una demostración científica o de cualquier otro tipo. La integración e inclusión de todos estos tipos de conocimientos múltiples tiene que ser horizontal y complementaria, puesto que ninguno de ellos podrá nunca albergar un entendimiento completo y definitivo. El conocimiento está abierto a una unidad infinita, como bien demostraron los teoremas de la incompletitud de Gödel.

El reconocimiento de la inconmensurabilidad del conocimiento nos obliga a aceptar que

International Security. Oxford: Oxford University Press, 2015.

49 BECK, Ulrich. La sociedad del riesgo mundial. En busca de la seguridad perdida. Barcelona: Paidós, 2008.

50 ESPINOSA RUBIO, Luciano. Variaciones biopolíticas sobre naturaleza y vida. In: ARBOR, vol. 189-762, julioagosto 2013, p. 11-12. 
cualquier teoría científica, creencia cultural, doctrina política o dogma religioso, serán siempre aproximaciones limitadas a la compleja red de fenómenos que inter-retro-actúan constantemente en la estructura ontológica de la realidad. Hacer frente a las problemáticas de la globalización requiere una ecología de saberes cuyo abordaje epistemológico abarque un diálogo transdisciplinar entre las propias disciplinas científicas y los saberes no científicos intrínsecos en las culturas ancestrales, la sabiduría indígena, la espiritualidad, las artes y otras formas de organización del conocimiento. Por este motivo, los la universalidad de los ODS requiere un abordaje multirreferencial donde converja la unidad en la diversidad y la diversidad en la unidad. Para eso es necesario reescribir la Historia de los subalternos de África, América Latina y Asia meridional.

Debemos cuestionarnos nuestro futuro común como especie en una sociedad-mundo enferma endémicamente. Tenemos que tomar consciencia de la patología del capitalismo y reaccionar en este preciso instante para aliviar los efectos de un cambio climático que ya se ha iniciado. Continuando con los mismos modelos de pensamiento, organización socio-económica insostenible, uso de energías contaminantes, destrucción de los ecosistemas naturales y confrontación bélica, sólo estaremos caminando hacia una aceleración de procesos que degradan la naturaleza y nos confinan hacia nuestra propia autodestrucción como especie. Por eso es urgente abandonar los modelos epistémicos paradigmáticos que los postulados capitalistas y el darwinismo social han constituido históricamente desde los siglos XVIII y XIX, puesto que nos han abocado a la crisis civilizatoria y ecológica actual. Tenemos que aprender a co-desarrollar en la Pachamama.

En este sentido, el sociólogo y analista del sistema-mundo Immanuel Wallerstein acierta al señalar que "el nuevo tema geocultural ya ha sido proclamado: es el tema de la identidad; identidad en cuanto incrustada en un concepto huidizo llamado «cultura» o, para ser más exacto, «culturas»" $" 51$. En efecto, debemos promover nuevos acercamientos epistemológicos para concebir que nuestra identidad es construida a partir de múltiples relaciones naturales y sociales, entendiendo que toda cultura es más o menos híbrida, mestiza, hecha de cruces, retro-alimentaciones... No existen culturas perfectas ni acabadas. Toda cultura lleva en sí misma suficiencias, insuficiencias, funcionalidades, disfuncionalidades...

Como señala el propio Dussel "las «etnicidades» de la humanidad se fueron generando en torno y desde un sistema asiático-africano-mediterráneo, que desde el siglo XV es, por primera vez, un «sistema mundial»" ${ }^{, 52}$. Por eso debemos promover un diálogo intercultural sin jerarquizaciones

51 WALLERSTEIN, Immanuel. El futuro de la civilización capitalista. Barcelona: Icaria, 1997, p. 91.

52 DUSSEL, Enrique. Ética de la liberación en la edad de la globalización y de la exclusión. $5^{\mathrm{a}}$ ed. Madrid: Trotta, 2006, p. 20. 
que desarrolle y potencialice alternativas epistémicas de cada cultura para conseguir los ODS, puesto que sólo la fecundación transcultural entre los pueblos nos podrá salvar de la barbarie a la que estamos encaminados como sistema-mundo. Ha llegado la hora de caminar juntos para los desafíos de un nuevo paradigma civilizatorio siguiendo el refrán africano que dice "si quieres ir rápido, ves sólo. Si quieres ir lejos, ves acompañado”. ¿Están preparados? Se anima a los lectores y lectoras a seguir adelante con cualquier pensamiento inspirado por las reflexiones presentadas en este trabajo que persigue el cumplimiento de los Objetivos de Desarrollo Sostenible desde una epistemología del Sur.

\section{Bibliografía}

BECK, Ulrich. La sociedad del riesgo mundial. En busca de la seguridad perdida. Barcelona: Paidós, 2008.

CASTELLS, Manuel. La era de la información. Vol. 1, la sociedad red. $2^{\mathrm{a}}$ ed. Torrejón de Ardoz: Alianza Editorial, 2000.

COLlADO-RUANO, Javier; GALEFFI, Dante A.; PONCZEK, Roberto I. The Cosmodernity Paradigm: An Emerging Perspective for the Global Citizenship Education Proposed by UNESCO. In: Transdisciplinary Journal of Engineering \& Science, TheATLAS, Vol. 5, pp. 2134, 2014.

D’AMBROSIO, Ubiratan. Transdisciplinaridade. São Paulo: Palas Athena, 1997.

DELEUZE, Gilles. GUATTARI, Félix. Mil mesetas: capitalismo y esquizofrenia. Valencia: PreTextos, 2006.

DUSSEL, Enrique. Ética de la liberación en la edad de la globalización y de la exclusión. $5^{\mathrm{a}}$ ed. Madrid: Trotta, 2006.

ESPINOSA RUBIO, Luciano. Variaciones biopolíticas sobre naturaleza y vida. In: ARBOR, vol. 189-762, pp. 1-14, julio-agosto 2013.

GOODY, Jack. The Theft of History. Cambridge: Cambridge University Press, 2006.

GROSFOGUEL, Ramón. "La desconolinazión de la economía política y los estudios postcoloniales: Transmodernidad, pensamiento fronterizo y colonialidad global". En Tabula Rasa, № 4, 17-48, Bogotá, 2006.

GUHA, Ranajit. Subaltern Studies I: Writing on South Asian History and Society. New Delhi: Oxford University Press, 1982.

GUHA, Ranajit; SPIVAK, Gayatri Chakravorty. Selected Subaltern Studies. New York: Oxford University Press, 1988.

HOUNTONDJI, Paulin J. "Conhecimento de África, conhecimentos africanos: duas perspectivas sobre os estudos africanos”. En Epistemologias do Sul, editado por Boaventura de Sousa Santos y Maria Paula Meneses, 131-144. São Paulo: Cortez, 2010.

MASOLO, Dismas A. "Filosofia e conhecimento indígena: uma perspectiva africana." En 
Epistemologias do Sul, editado por Boaventura de Sousa Santos y Maria Paula Meneses, 313240. São Paulo: Cortez, 2010.

MIGNOLO, Walter. Historias Locales/Diseños Globales: Colonialidad, Conocimientos subalternos y pensamiento fronterizo. Madrid: Akal, 2003.

- Capitalismo y geopolítica del conocimiento. El eurocentrismo y la filosofía de la liberación en el debate intellectual contemporáneo. Buenos Aires: El signo, 2001.

MOOSA, Ebrahim. "Transições no "progresso" da civilização: teorização sobre a história, a prática e a tradição". En Epistemologias do Sul, editado por Boaventura de Sousa Santos y Maria Paula Meneses, 291-312. São Paulo: Cortez, 2010.

MORIN, Edgar. Introdução ao Pensamento Complexo. Lisboa: Instituto Piaget, 2008.

NICOLESCU, Basarab. O Manifesto da Transdisciplinaridade. São Paulo: TRIOM, 2008.

QUIJANO, Aníbal. "Colonialidad del poder. Cultura y conocimiento en América Latina". En Capitalismo y geopolítica del conocimiento. El eurocentrismo y la filosofía de la liberación en el debate intellectual contemporáneo, editado por Walter Mignolo (ed.), 117-132. Buenos Aires: El signo, 2001.

. "Colonialidade do poder e classificação social. En Epistemologias do Sul, editado por Boaventura de Sousa Santos y Maria Paula Meneses 84-130. São Paulo: Cortez, 2010.

RAMOSE, Mogobe B. "Globalização e Ubuntu". En Epistemologias do Sul, editado por Boaventura de Sousa Santos y Maria Paula Meneses, 175-220. São Paulo: Cortez, 2010.

RIECHMANN, Jorge. Un buen encaje en los ecosistemas. $2^{\mathrm{a}}$ ed. (revisada) de Biomímesis. Madrid: Ed. Catarata, 2014.

ROBERTSON, Roland. Globalization. Social Theory and Global Culture. London: SAGE, 1992.

SANTOS, Boaventura de Sousa. Toward a New Common Sense: Law, Sciencie, and Politics in the Paradigmatic Transition. New York: Routledge, 1995.

. "Para além do pensamento abyssal: das linhas globais a uma ecologia de saberes". En Epistemologias do Sul, editado por Boaventura de Sousa Santos y Maria Paula Meneses 31-83. São Paulo: Cortez, 2010a.

"Um Ocidente não-ocidentalista? A filosofia à venda, a douta ignorância e a aposta de Pacal". En Epistemologias do Sul, editado por Boaventura de Sousa Santos y Maria Paula Meneses, 519-562. São Paulo: Cortez, 2010b.

SPIVAK, Gayatri Chakravorty. ¿Puede hablar el subalterno?. Buenos Aires: El cuenco de plata, 2011.

SIPRI (Stockholm International Peace Research Institute). Yearbook 2015. Armaments, Disarmament and International Security. Oxford: Oxford University Press, 2015.

TORRES, Nelson. A topologia do ser e a geopolitica do conhecimento. Modernidade, império e colonialidade. En SANTOS, Boaventura de Sousa, y MENESES, Maria Paula (org.), Epistemologias do Sul. Pp. 396-443. São Paulo: Cortez, 2010.

VISVANATHAN, Shiv. "Cultural Encounters and the Orient: a Study in the Politics of Knowledge". En Diogenes, 50 (4), 69-81, 2003.

WACKERNAGEL, Mathis, REES, William E. Our Ecological Footprint. Reducing Human Impact on the Earth. Gabriola Island: New Society Publishers, 1996. 
WALLERSTEIN, Immanuel. El futuro de la civilización capitalista. Barcelona: Icaria, 1997.

WORLD WILDLIFE FUND (WWF). Living Planet Report 2014. Species and Spaces, People and Places. 2014.

Recebido em 27/05/16 - Aprovado em 06/07/16 